

\author{
Volume 12 \\ Número 2 \\ Agosto/Setembro de 2018
}

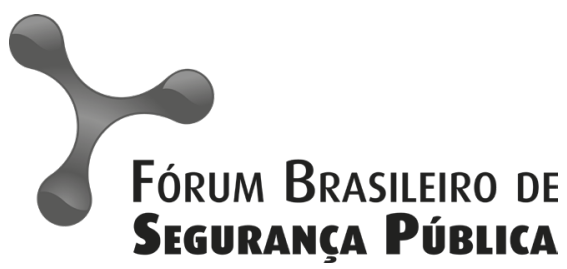

ISSN 1981-1659 


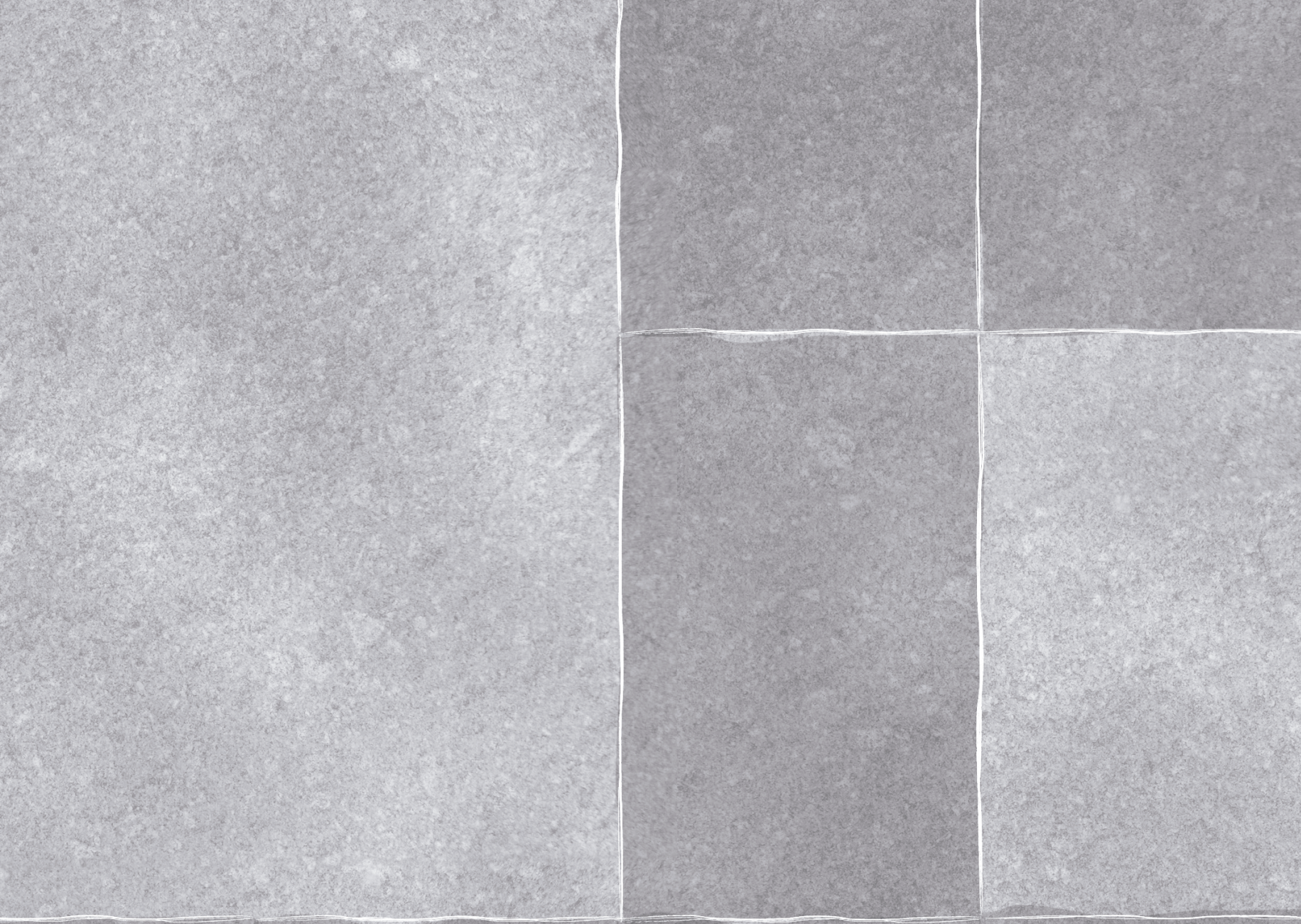




\title{
A Análise de Redes Sociais para o Es- tudo de Gangues: uma abordagem a partir da teoria de grafos
}

\section{Antonio Hot Pereira De Faria}

Bacharel em Ciêncios Militares - Academia de Polício Militar de Minas Gerais, Química - Universidade Federal de Minas Gerios, Mestre em Administração - Faculdade de Estudos Administrativos de Minas Gerais, Doutor em Geografia: tratamento da informação espacial - Pontifícia Universidade Católica de Minas Gerais. Capitõo da Polício Militar de Minas, Comandante de Companhio ROTAM, professor e pesquisador do Academio de Polício Militar.

\section{Diego Filipe Cordeiro Alves}

Diego Filipe Cordeiro Alves Geógrafo, Mestre e Doutorando em Geografia - Tratamento da Informação Espacial - Pontifícia Universidade Católica de Minas Gerais, com atuação nas áreas de Sistemas de Informações Geográficas, Sensoriamento Remoto e Análise Espaciol

\section{Alexandre Magno Alves Diniz}

Possui Graduação em Publicidade e Propaganda pela PUCMinas, Mestrado em Geografia - Konsas State University (EUA), Doutorado em Geografia - Arizona State University (EUA) e Pós-Doutorado em Geografio - McGill University. Professor adjunto IV do Programa de Pós-Graduação em Geografia da PUCMinas.

\author{
Data de recebimento: $31 / 05 / 2018$ \\ Data de aprovação: 05/11/2018 \\ DOI: 10.31060/rbsp.2018.v12.n2.943
}

\begin{abstract}
Resumo
O artigo aborda a conformação de uma gangue oriunda de um aglomerado subnormal de Belo Horizonte e que atua na copital e outros municipios mineiros. Utilizou-se como base teorias sobre a análise de redes sociais e grafos. O instrumental da pesquisa contou com análise documental de boletins de ocorrência policial dos eventos perpetrados pelos agentes envolvidos na formação da gangue no período de 2006 a 2014. Foi utilizado o plugin NodeXL como recurso para análise de redes. As conexões criminais foram identificadas por meio do atuaçõo conjunto de outores de delito num mesmo evento. Descreveu-se como se dá a estruturação e desenrolar de vínculos (estrutura topológica) entre indivíduos em uma rede configurada pela gangue estudada. Os resultados de medidas de centralidade (grau, centralidade de proximidade, centralidade de intermediação, centralidade de outovetor) e métricas (distôncio geodésica, diâmetro, densidade e modularidade) permitiram identificar que a gangue represento uma rede social coesa e foi possível identificar os principais individuos em termos de importôncia para os vínculos criminais no gangue.
\end{abstract}

Palavras -Chave

Gongue; Análise de Redes Sociais; Grafo. 


\section{Abstract \\ Analysis of Social Networks for the Study of Gangs: an approach based on graph theory}

The article approaches the conformation of a gang from a favela of Belo Horizonte and that operates in the capital and other cities of Minas Gerais. Theories based on the social networks analysis and graphs were used as basis. The research instrument consisted of documentary analysis of police records of the events perpetrated by the agents involved in the formation of the gang from 2006 to 2014. An exploratory plug-in (NodeXL) was used for network analysis, which allowed the exploration of network graphics. It was possible to identify the criminal links by the relationship of the individuals in the same police report. It was described how the structuring and unrolling of links (topological structure) between individuals occurs in a network configured by the studied gang. It was described how the structuring and unrolling of links (topological structure) between individuals occurs in a network configured by the studied gang. The results of measures of centrality (degree, centrality of proximity, centrolity of intermediation, centrality of eigenvector) and metrics (geodesic distonce, diameter, density and modularity) allowed to identify that the gang represents a cohesive social network, in which it is possible to identify the main elements in terms of importance for criminal gong links through the proposed methodology.

\section{Keywords}

Gang; Social Networks Analysis; Graph. 


\section{INTRODUÇÃO}

$\Delta$ formação, estrutura e comestudos, que buscam melhor compreender esse fenômeno diretamente relacionado à criminalidade e violência urbana.

Numa revisão bibliográfica, Beato e Zilli (2012) apontam como principais estudos elaborados para abordar os fenômenos da criminalidade e da violência ligados à atuação de gangues ou grupos armados ilegais que atuam em vilas, favelas e bairros pobres de periferia dos grandes centros urbanos brasileiros os trabalhos de Misse (1997, 2008); Abramovay et al. (1999); Amorim (2006); Barcellos (2003); Beato et al. (2001); Leeds (1998); Paes Manso (2005). Entretanto, tais trabalhos não abordam a questáo da estrutura interna dos grupos de maneira a identificar os vínculos existentes e relacionamentos criminais decorrentes.

Destaca-se como uma das abordagens inaugurais para o entendimento da formaçáo de gangues a posição estrutural de classe por jovens envolvidos com comportamentos delinquentes, provenientes de classes mais baixas (ASHBURY, 1927; THRASHER; SHORT, 1963; ZORBAUGH, 1929).
Segundo Sánchez-Jankowski (1991, 1997), a maior parte das pesquisas norte-americanas define as gangues com base em três pressupostos: associação fracamente estruturada de indivíduos; predominância em atos delituosos ou crimes de natureza econômica ou violentos e atuaçáo numa base territorial. Segundo o autor, a melhor definição para gangue é

[...] um sistema social organizado que é ao mesmo tempo quase privado (isto é, não totalmente aberto ao público) e quase secreto (isto é, a maior parte das informaçóes sobre suas atividades permanece restrita ao grupo), cujo tamanho e objetivos tornam indispensável que a interaçáo social seja dirigida por uma estrutura de liderança com papéis bem definidos; em que a autoridade ligada a esses papéis é tão legitimada que os códigos sociais regulam tanto o comportamento dos líderes quanto o das bases; que planeja e provê náo somente serviços econômicos e sociais para seus membros quanto sua própria manutençáo como organizaçāo; que persegue esses objetivos a despeito da legalidade ou ilegalidade das atividades e que não tem uma burocracia (isto é, um pessoal administrativo hierarquicamente organizado e distinto da liderança) (SÁNCHEZ-JANKOWSI, 1997). 
Assim, gangue é um tipo de relação social entre indivíduos, e que, portanto, pode ser representada por meio de uma rede.

O conceito de rede, embora náo produza uma teoria para o estudo dos fenômenos sociais, oferece um arcabouço analítico que congrega as interaçóes sociais de determinados grupos. $\mathrm{O}$ estudo destas redes permite analisar diferentes aspectos relativos aos autores e suas relaçóes (MORSELLI, 2009).

Logo, a análise de redes sociais pode contribuir para a análise estrutural das gangues, que é uma abordagem que estuda as ligaçôes relacionais entre atores sociais. Esta metodologia tem por base que as relações entre os indivíduos ocorrem numa estrutura em forma de redes. As redes, por sua vez, podem ser representadas por meio de um grafo, o que permite a análise de suas características fundamentais e de suas estruturas topológicas. O conhecimento da estrutura, propriedade e funçáo é fundamental para entender a manutenção da funcionalidade dessas redes.

Nesse trabalho, propóe-se realizar um estudo de caso dos autores de delitos envolvidos numa mesma gangue que atua em Belo Horizonte, a partir de suas coparticipaçóes em mesmos eventos e, a partir da análise de redes sociais por meio da teoria de grafos, buscar entender os vínculos existentes e extrair informaçóes que permitam inferir sobre a estrutura hierárquico-funcional dos membros.

Em âmbito acadêmico, a justificativa do estudo reside no fato de que poucos estudos foram empreendidos na tentativa de se compreender as estruturas sociais dos componentes que formam as gangues $\mathrm{e}$ grupos delinquentes em contexto urbano, o que permite contribuir para as reflexóes sobre a temática com dados empíricos. Além disso, a melhor compreensão do fenômeno potencializa as ações de controle e combate à criminalidade organizada.

\section{Análise de Redes para o Estudo de Or- ganizações Criminosas: Uma Revisão Bi- bliográfica}

O objetivo dessa seção é realizar uma breve apresentaçáo dos principais trabalhos que utilizaram a análise de organizaçôes criminosas, a partir da abordagem de redes sociais, a fim de se criar um quadro conceitual e metodológico que contribua como eixo de análise apropriado pela literatura especializada do objeto deste estudo.

As abordagens de rede em estudos do fenômeno criminal se tornam mais comuns a partir da década de 1990, especialmente a partir da ascensão do conceito de rede como principal estrutura organizacional de relacionamentos sociais, sejam estes criminais ou não (MORSELLI, 2009).

Embora o crime seja um fenômeno social, as redes criminais possuem especificidades em função de sua estrutura, ação e objetivos. Dadas suas características, as redes criminais experimentam a oposiçáo entre, de um lado, a necessidade de se manter em segredo e, de outro, a necessidade de se coordenar as informações e atividades dos membros que a compóem (BAKER; FAULKNER, 1993, p. 844).

Os estudos pioneiros de redes sociais 
criminais enfocaram grupos específicos, com destaque para os estudos elaborados em contextos prisionais (MORENO; WHITIN; JENNINGS, 1932; JENNINGS, 1943 apud MORSELLI, 2009, p. 3). Os dados a respeito destas redes foram analisados em diferentes oportunidades, permitindo a identificação de subgrupos, solidariedade e hierarquias. Observa-se, portanto, que as redes sociais criminais são mais que apenas redes sociais operando em contextos criminais. Os estudos de Erickson (1981 apud MORSELLI, 2009) partem deste princípio, indicando que o sigilo e o risco são condições inerentes à existência destas redes. Desta forma, diferentes estratégias são adotadas para se evitar uma detecçáo da rede, tais como a limitação das interaçôes físicas e minimização dos canais de comunicação.

Em The Social Organization of Conspiracy: Illegal Networks in the Heavy Electrical Equipment Industry, os autores Baker e Faulkner (1993) analisam a formação de redes de conspiração no setor de equipamentos elétricos industriais, ocorrida na década de 1950 nos EUA.

Partindo do pressuposto de que uma organização é um sistema social completo, com diferentes relacionamentos interdependentes, os autores propóem uma abordagem destas a partir de um conceito de redes (BAKER; FAULKNER, 1993, p. 844).

A partir dos dados contidos nos processos judiciais, aos quais as organizaçóes foram expostas e dos vereditos dos seus membros, os autores constroem as redes de colaboração das conspiraçóes em análise, verificando medidas de centralidade e densidade dos vértices e dos grafos, respectivamente. Dentre as hipóteses verificadas, observou-se como a posição de um determinado membro em sua rede aumentava seu risco de condenaçáo e a intensidade de sua pena, além de verificar o grau de exposiçáo dos membros de cada rede em função da densidade e organizaçáo da mesma.

As medidas de centralidade dos vértices foram utilizadas para avaliar os indivíduos das redes (membros das empresas), enquanto as medidas de densidade e centralização do grafo foram utilizadas para avaliar as organizaçóes propriamente ditas. No trabalho cada companhia foi tratada como uma rede, sendo composta pelos vértices (empregados) e arestas (relacionamentos entre os mesmos).

Observou-se que o tamanho das redes (Companhias investigadas) não influenciou diretamente nos vereditos obtidos. Diferentemente do esperado, nas redes mais centralizadas os membros foram menos propensos a serem considerados culpados do que nas redes descentralizadas. Os membros de maior centralidade (maior centralidade do vértice) foram mais expostos, possuindo maior probabilidade de um veredito de culpado.

Dentre os principais fatores que contribuíram para uma condenação dos membros das redes, os autores apontam a centralidade de cada membro na rede, a participaçáo em uma rede descentralizada e a ocupaçáo de uma posição de destaque em uma rede centralizada (BAKER; FAULKNER, 1993).

Krebs (2002) em seu trabalho intitulado Mapping Networks of Terrorist Cells 
investiga o arranjo da rede de terroristas que participaram ou colaboraram para os atentados terroristas ocorridos em 11 de setembro de 2001 nos EUA. Embora desde as primeiras horas após os atentados terem sido veiculadas informaçóes que davam conta da existência de uma "rede terrorista”, a estruturação de tal rede só pôde ser realizada em etapa posterior.

As redes de organizaçóes criminosas apresentam três fatores dificultadores aos pesquisadores que se dedicam ao tema: incompletude em função de links e nós que não puderam ser descobertos, dificuldades em se determinar uma fronteira exata do alcance da rede e caráter dinâmico destas (SPARROW, 1991 apud KREBS, 2002, p. 44).

Krebs (2002) classifica os membros participantes das redes (vértices) em três categorias de força dos laços em função da quantidade de tempo de convivência entre os mesmos. A partir dos nomes dos membros da organização e de sua localização foi estruturada uma rede de colaboraçóes, Observou-se que, embora estivessem em um mesmo avião durante os atentados, os membros de uma mesma célula terrorista viviam em localidades distantes. Tal estratégia objetivava manter a integridade da organização em caso de captura de um ou mais membros.

Dentre os terroristas, observou-se que aquele considerado líder da conspiração pelas autoridades possuía maiores índices de centralidade e proximidade na rede de colaborações, assim como os pilotos (membros os quais possuíam conhecimentos específicos para os objetivos do atentado) (KREBS, 2002).
$\mathrm{Na}$ obra Inside Criminal Network, Morselli (2009), a partir de uma breve explanação da evolução do estudo do crime sob a perspectiva do indivíduo, enfatiza o conceito de redes sociais criminais, considerando que grande parte dos crimes são cometidos por mais de uma pessoa. Desta forma, o conceito de redes criminais ou redes sociais criminais é importante para a análise do fenômeno criminal (MORSELLI, 2009, p. 1).

Do ponto de vista da operacionalização dos estudos de redes sociais, destaca-se a utilização os estudos de métricas baseadas em teorias de grafos. Os conceitos de centralidade foram apresentados por Bavelas (1948) e posteriormente estruturados por Freeman (1979). Do ponto de vista do indivíduo, a centralidade em uma rede representa o alcance do mesmo em número de contatos e interaçóes. Embora as posiçóes centrais sejam estratégicas, as mesmas proporcionam maior visibilidade e, portanto, fragilidades. Apesar do papel estratégico, tal posiçáo pode ser encarada como uma posição de vulnerabilidade, uma vez que o aumento dos contatos e interaçóes pode levar a uma exposiçáo da atividade criminal.

Além das posições de centralidade, possui importante destaque as posiçóes de intermediação nas redes. Estas posiçóes são indicadas pela medida betweenness centrality, mostrando o papel estratégico de trânsito de informaçôes pelos autores. Um intermediário se posiciona entre dois membros não conectados da rede, estabelecendo uma ligaçáo entre os mesmos (MORSELLI, 2009, p. 15-16). 
Comet (2011), em seu trabalho Anatomy of a Fraud: Trust and Social Networks foca na estrutura social de uma fraude fiscal em estrutura de Pirâmide de Ponzi ocorrida entre os anos de 1986 e 1999, envolvendo militares e civis na Groenlândia. Tomando por base que as fraudes financeiras se baseiam na agregação de novos membros à rede a partir do contato com membros que já fazem parte desta, $o$ autor analisa o papel da confiança e o nível de convívio social na manutenção deste esquema.

Relaçóes de mercado, especialmente aquelas marcadas por algum nível de incerteza, baseiam-se em algum grau em relaçóes de confiança. A proximidade a partir de relaçóes sociais, ao gerarem confiança, oferecem as condições necessárias às fraudes desta tipologia (BAKER; FAULKNER, 2004 apud COMET, 2011, p. 46).

A fraude apresentada no estudo de caso só se tornou possível a partir da existência de confiança entre os membros da rede e os "vendedores" dos investimentos apresentados. Além disso, a existência de pessoas no mesmo círculo social que as vítimas serviu de uma espécie de "garantia" aos novos membros da pirâmide financeira. $\mathrm{O}$ caso em estudo segue o padrão das demais fraudes financeiras: as fases de início, desenvolvimento e declínio (COMET, 2001, p. 48).

Três aspectos foram decisivos na estruturaçáo do esquema de fraude investigado pelo autor: a intensidade das relaçóes entre os membros, a frequência da interaçáo e a duraçáo do relacionamento (COMET, 2001, p. 54).
Desta forma, os vínculos sociais em rede foram utilizados como método de recrutamento pelos operadores do esquema de fraude, o que tornou possível a rápida expansáo do esquema. Ressalta-se que, do total de entrevistados, ao menos $55 \%$ possuíam relacionamentos próximos ou relativamente próximos com as pessoas que os recrutaram ou que foram utilizadas como exemplos de sucesso para incentivo (COMET, 2011, p. 55).

Bakker; Raab; Milward (2011) no trabalho A Preliminary Theory of Dark $\mathrm{Ne}$ twork Resilience tratam da capacidade de resiliência das redes a partir das características das mesmas.

O conceito de dark network se relaciona às redes sociais que operam de maneira secreta e ilegal, se relacionando às atividades de gangues e demais redes sociais criminais. O termo dark network pode ser entendido como "redes secretas operando ilegalmente, além dos limites da lei" (MILWARD \& RAAB, 2006; RAAB \& MILWARD, 2003 apud BAKKER; RAAB; MILWARD, 2011, p. 33).

O estudo se difere das análises usuais sobre redes criminais dedicadas ao estudo da estrutura e da dinâmica interna das redes e ao estudo descritivo/histórico do contexto de formação das mesmas.

Com relação ao termo resiliência, a pesquisa o relaciona a duas condiçóes básicas: a exposição a ameaças, estresse e adversidades e a capacidade de adaptação positiva a estas circunstâncias. A capacidade de resiliência se manifesta como a robustez dos sistemas em absorver os choques e ad- 
versidades vindos de fora e a capacidade de se reorganizar e reinventar a partir destes choques (MOBERG \& FOLKE, 1999 apud BAKKER; RAAB; MILWARD, 2011, p. 35).

Bakker; Raab; Milward (2011) concluem que os recursos dos quais as redes dispóem influenciam positivamente na resiliência destas às interferências externas. A legitimidade interna e externa das propostas destas redes atua de maneira similar, possuindo correlaçáo positiva com a capacidade de resiliência da mesma.

Com relação às capacidades de organizaçáo da própria rede, os atores apontam como características básicas a capacidade de substituir nós e arestas e a capacidade de equilibrar integração e diferenciaçáo dentro da rede. Quão maior a capacidade de substituir arestas e nós uma rede possui, maior sua resiliência, uma vez que esta capacidade permite que a mesma continue funcionando mesmo após a prisão de integrantes ou a perda de conexốes previamente estabelecidas. A centralizaçáo da rede em poucos integrantes atua como um fator de baixa resiliência, uma vez que potencializa o impacto de um determinado choque a partir da retirada de membros estratégicos. (BAKKER; RAAB; MILWARD, 2011, p. 54-55).

\section{Uso de Grafos para Análise de Redes So- ciais}

O tema rede social e a análise de redes sociais concentra interesse em pesquisas sobre relacionamentos entre as entidades sociais e nos padróes e implicaçóes desses relacionamentos (WASSERMAN; FAUST, 1994).
Os métodos de análise de rede social permitem identificar aspectos, tais como, a) padróes de relacionamento entre os atores de uma rede; b) a conectividade entre os mesmos; c) a formaçáo de clusters; d) a evolução da rede ao longo do tempo; e e) o fluxo de comunicação, informação e conhecimento dentro da rede (BORDIN; GONÇALVES; TODESCO, 2014).

Em uma análise de redes sociais, dois elementos são importantes: o ator e o laço relacional. Um ator é uma unidade discreta, que pode ser uma pessoa, ou um conjunto discreto de pessoas agregadas em uma unidade social coletiva, organizaçóes ou outras coletividades; já o laço relacional ou ligação (linkage) é responsável por estabelecer a ligação entre pares de atores (MATHEUS; SILVA, 2006). Os laços, portanto, são responsáveis por promoverem a ligaçáo entre pares de atores.

Grafo é definido de maneira unânime pelas publicaçóes como sendo:

Um grafo $\mathrm{G}(\mathrm{N}, \mathrm{L}$ ), algumas vezes chamado gra-
fo não direcionado (undirected graph) consiste de
dois conjuntos de informaçóes: um conjunto de
nós (node), $\mathrm{N}\{\mathrm{n} 1, \mathrm{n} 2, \ldots$, ng), e um (ou mais)
conjunto(s) de linhas, $\mathrm{L}\{11, \mathrm{l}$, ..., IL), entre pa-
res de nós (WASSERMAN, FAUST, 1999, pp
94-96).

Um grafo possui vértices adjacentes caso estes definam uma aresta, isto é, se ( $a, b)$ é uma aresta do grafo, então $(a, b)$ incide em "a" e em "b". Diz-se que há um caminho quando se tem uma sequência de arestas adjacentes e distintas. O caminho poderá ser aberto ou fechado, sendo que, caso seja fechado, tem-se um grafo 
é cíclico, do contrário, o grafo é acíclico. Um vértice "alcançă" outro quando há um caminho que liga esses vértices. $\mathrm{O}$ grau do vértice do grafo é o número de incidências de arestas que ele recebe. Quando uma aresta possui vértices coincidentes, há um laço. Arestas são paralelas se elas compartilharem o mesmo par de vértices extremos. O grafo poderá ser classificado como simples, caso não tenha laço nem arestas paralelas, o grafo é como conexo, se a partir de um vértice qualquer se alcança todos os demais vértices, ou, pelo contrário, será desconexo. Um vértice é isolado se não há arestas partindo dele. O grafo será valorado quando suas arestas e/ou vértices estão relacionados a algum atributo (peso). Os grafos podem ser representados por diversas formas, destacando-se as matrizes (úteis para manipulaçôes matemáticas) e a geométrica, que facilita a compreensão (BARROSO, 1998).

As propriedades de um grafo em termos estruturais podem ser verificadas por medidas e métricas do grafo. Para tanto, o pesquisador deve identificar preliminarmente a variável estrutural que colocam em relaçáo os atores do sistema social em estudo (HIGGINS; RIBEIRO, 2018). Para este trabalho a variável estrutural são as ocorrências com participaçáo de agentes envolvidos no grupo delinquente.

\section{Medidas de Centralidade}

As medidas de centralidade representam a iniciativa e prestígio dos atores na estrutura da rede social. Numa estrutura reticular, é possível discriminar os nós conforme nível de atividade ou popularidade. Ou seja, a centralidade permite mensurar e identificar o poder num sistema social (HIGGINS; RIBEIRO, 2018).
Dentre as medidas de centralidade, utilizadas desde 1950 por Bavelas (1950) em redes sociais, destaca-se como sendo principais as descritas por Freeman (1979) em estudo de revisão: centralidade de grau, centralidade de proximidade e centralidade de intermediação. Além destas, tem-se a centralidade de autovetor proposta por Bonacich (1987), que também será utilizada neste trabalho.

A centralidade de grau (degree centrality) refere-se à quantidade de ligaçóes que um vértice possui. A centralidade nesse caso é dada pelo grau (dk) do vértice $\mathrm{k}$, que é definido pela equação a seguir:

$$
C_{d}\left(v_{k}\right)=d_{k}=\sum_{j=1}^{n} a_{k j}
$$

No estudo da estrutura de gangue, a centralidade de grau mede quais indivíduos possuem mais conexóes com outros indivíduos dentro da rede que representa a gangue.

Nem sempre as relaçóes entre atores de uma mesma rede se limitam aos seus vizinhos imediatos. Há casos em que as interaçóes entre atores não adjacentes podem depender de atores intermediários. "Intermediar é uma forma de poder dentro de uma rede, pois outorga a capacidade de facilitar ou obstruir, de forma seletiva, fluxos de informaçáo ou de recursos que circulam por uma estrutura reticular" (HIGGINS; RIBEIRO, 2018, p. 149-150).

A centralidade de intermediaçâo (betwenness centrality) mede a frequência com que um vértice está presente em um caminho geodésico (menor caminho) entre 
quaisquer outros dois vértices do grafo. É calculada conforme a equação seguinte, em que $\mathrm{i} \neq \mathrm{j} \neq \mathrm{k}$, dikj é o número de caminhos geodésicos entre i e j que passam por $\mathrm{k}$ e dij o número de caminhos geodésicos entre i e j.

$$
C_{b}\left(v_{k}\right)=\frac{\sum d_{i k j}}{\sum d_{i j}}
$$

A centralidade de intermediação reflete quais indivíduos são mais importantes para a conexáo entre os membros da rede, visto que são mais centrais quanto às ligaçóes entre dois outros componentes da gangue.

A medida da velocidade em que uma informação ou recurso flui através da rede é representada pela centralidade de proximidade, sendo uma capacidade de influência dos atores que compóem a estrutura social. A centralidade de proximidade (closeness centrality) é calculada para cada vértice obtendo o inverso da soma de distâncias desse vértice para todos os outros vértices do grafo e é calculada por meio da equação adiante, em que dist (vj, vk) é a distância (comprimento do menor caminho) entre o vértice vj e vk.

$$
C_{c}\left(v_{k}\right)=\frac{1}{\sum_{j=1}^{n} \operatorname{dist}\left(v_{j}, v_{k}\right)}
$$

A centralidade de proximidade mede quais componentes da rede estão mais próximos e aqueles que estão mais distantes de todos os outros na rede.

A centralidade de autovetor (eigenvector centrality) é baseada em autovalores e autovetores de matrizes simétricas. Esta medida de centralidade visa medir a importância de um vértice em função da importância de seus vizinhos. Assim, mesmo que um vértice possua poucas conexôes com a estrutura geral do grafo, ou seja, está conectado somente a alguns outros vértices da rede (centralidade de grau baixa), mas se seus vizinhos são "importantes", o vértice também será também importante, por este parâmetro, obtendo uma centralidade de autovetor elevada. Assim, a centralidade de autovetor é uma medida relacional que pode exprimir atores que aparentemente não possuem importância, mas que, por suas ligaçóes, também se tornam importantes pela centralidade de seus vizinhos. Segundo Ruhnau (2000), a medida de centralidade de autovetor classifica o vértice como mais central na medida em que ele estabeleça relaçóes com elementos que também estejam em uma posição central.

Para este trabalho, numa estrutura de gangue, um elemento que possui valor alto de centralidade de autovetor está conectado a elementos que também se conectam a um grande número de elementos, o que potencializa a sua importância em termos de relacionamentos na estrutura da gangue.

\section{Métricas do Grafo}

Dentre os parâmetros possíveis de serem analisados num Grafo, para este trabalho, possuem relevância os aspectos: distância geodésica, diâmetro, densidade e modularidade.

A distância geodésica é o menor caminho, expresso pelo número de arestas que liga dois vértices de uma rede. Em uma 
gangue, a distância de um autor que praticou um delito com outro autor é 1 . Dois autores de crime que náo praticaram eventos conjuntamente, mas compartilham um autor em comum, possuem distância $2 \mathrm{e}$, assim por diante.

Diâmetro é a distância geodésica máxima existente num grafo. Relaciona-se à quantidade de tempo que a informaçáo leva para passar através de toda a rede. No contexto de uma rede que representa uma gangue, indica a possibilidade de colaboração mais longa entre os membros.

A densidade (density) refere-se ao nível geral de ligaçóes entre os pontos de um grafo. Quanto mais pontos estão ligados uns aos outros, mais denso será o gráfico. No contexto da análise estrutural de gangues, a densidade reflete quanto do total de uma rede que um componente da gangue foi coautor de um evento criminal.

A modularidade (modularity): é uma medida de avaliação da qualidade de agrupamento de um grafo. É uma das métricas mais utilizadas na identificação de comunidades. A modularidade possui valores entre $[0,1]$, sendo que os valores próximos a 1 indicam uma boa qualidade de agrupamento, o que pode ser atribuído a grande quantidade de arestas no interior dos grupos (BELIZARIO, 2012,). Para o presente trabalho, a modularidade indica quão agrupada é a rede que representa a gangue em estudo.

\section{Identificação de comunidades}

Numa rede, conforme já expresso, os indivíduos são representados por nós e suas relaçóes por arestas. As comunidades em uma rede são conjuntos de indivíduos que compartilham características similares
(BELIZARIO, 2012).

Dentre as características mais importantes numa rede pode-se citar a estrutura de comunidades, ou agrupamentos de nós da rede. Essa estrutura de comunidades é a organização dos nós em grupos, nos quais há uma maior densidade de arestas entre os nós que compóem uma mesma comunidade e uma menor densidade de arestas entre os nós de comunidades distintas (BELIZARIO, 2012). A Figura 1, exemplifica uma estrutura de comunidades.

As métricas utilizadas para descrever a posição dos indivíduos ou atores na rede, como as de centralidade, são alvos de pesquisas que tem por objetivo trazer elementos para essa fundamentação, bem como testar sua validade. Tais medidas buscam vincular a posição do indivíduo dentro da estrutura da rede, com relação à sua influência interpessoal, ao acesso à informação, às relaçóes de poder, dentre outras (PARREIRAS et al., 2006).

Nesse estudo, em que pese não haver objetivo de descrever hierarquicamente os componentes da gangue, buscar-se-á compreender quem são os elementos-chave na estrutura da gangue, por meio das medidas de centralidade, métricas e estudo de comunidades dentro da rede.

\section{Caracterização do Objeto de Estudo}

Neste trabalho foi estudada uma gangue atuante no aglomerado subnormal do Alto Vera Cruz, situado na regiáo Leste de Belo Horizonte. Conforme será explorado adiante, a atuaçáo da gangue conta com 130 agentes os quais cometeram 225 ocorrências policiais no período de 2006 a 2014.

A área de atuação da gangue envolve 


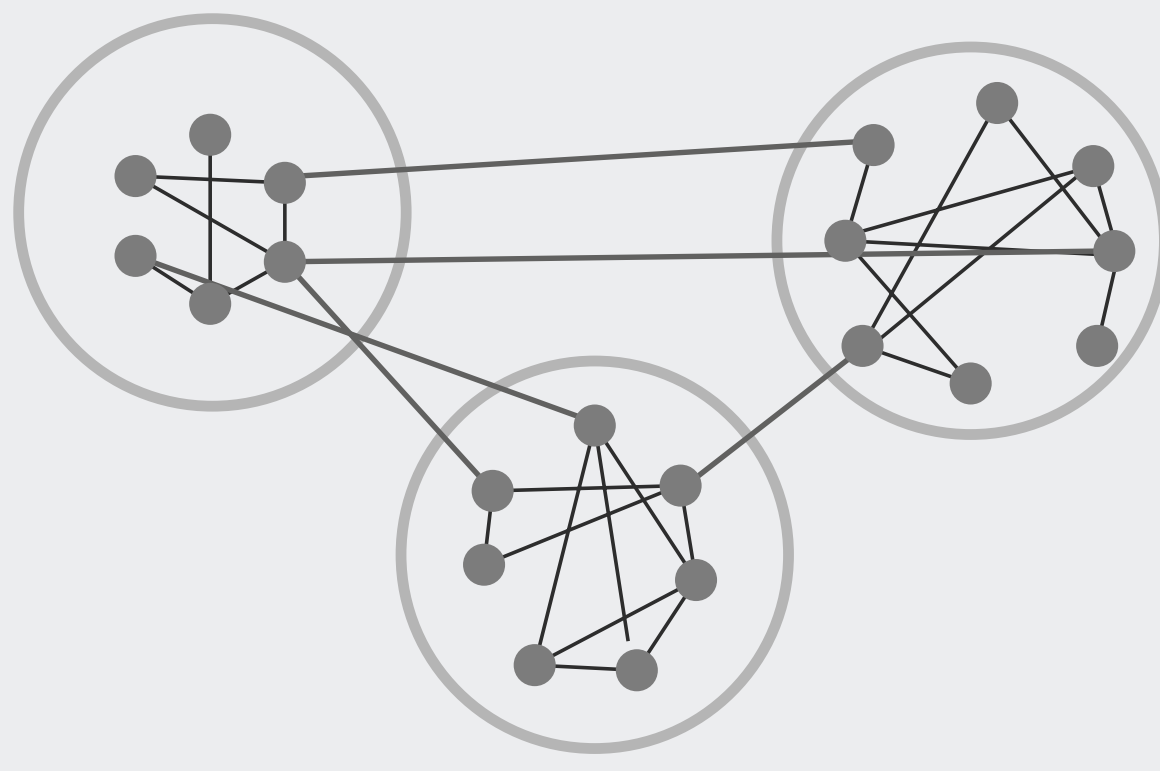

eventos perpetrados em Belo Horizonte e outros 21 municípios, dentro e fora da região metropolitana de Belo Horizonte (RMBH).

Em termos de tipologia criminal, 67\% dos eventos referem-se aos crimes contra o patrimônio, dos quais há relevância do furto a residência ( $42 \%$ do total de registros) e o roubo a residência ( $11 \%$ do total de registros). A segunda modalidade mais presente, o tráfico de drogas, representa $20 \%$ do total de ocorrências. O porte ilegal de arma de fogo figura como terceira categoria mais presente, contando $8 \%$ do total de registros. O homicídio (tentado e consumado), contou com nove eventos (3,5\% das ocorrências).

\section{Materiais e Métodos}

Trata-se de um Estudo de Caso, já que se buscou por meio da análise de um único caso, reunir dados empíricos capazes de permitir uma análise que contribuísse para e fomentasse outros estudos similares na mesma linha de pesquisa.

Para se atingir os objetivos da pesquisa, primeiramente, buscou-se analisar os vínculos entre os indivíduos que compóem a gangue, na sequência, passou-se a analisar os relacionamentos criminais, de forma a configurar os vínculos por meio de uma estrutura de rede.

A identificação da gangue se deu a partir de informaçóes de inteligência de segurança pública, pelo envolvimento em eventos criminais no local de estudo, a partir da delimitaçáo espacial das ocorrên- 
cias e da moradia dos agentes envolvidos no aglomerado subnormal escolhido para a pesquisa, o Alto Vera Cruz. O recorte temporal envolveu eventos cometidos entre $01 / 01 / 2006$ a 31/12/2014.

Utilizou-se a documentação indireta por meio da análise dos boletins de ocorrência registrados pela Polícia Militar de Minas Gerais e pela Polícia Civil de Minas Gerais, que são denominados de Registros de Evento de Defesa Social (REDS), os quais contaram com o envolvimento como autores de delito de indivíduos pertencentes à mesma gangue. $\mathrm{O}$ recorte de eventos criminais utilizado desconsiderou os crimes de menor potencial ofensivo, previstos na Lei 9099 de 26 de setembro de 1995 (BRASIL, 1990).

A partir daí elaborou-se uma matriz contendo todos os relacionamentos por ocorrência, sendo utilizado um plugin de análise exploratória de redes NodeXI (programa de código aberto para o $\mathrm{Mi}$ crosoft $^{\oplus}$ Excel $^{\oplus}$, versão 1.0.1.337, que permitiu a configuração dos dados em forma de uma rede). Por essa técnica foi possível identificar os vínculos criminais pelo relacionamento dos indivíduos numa mesma ocorrência. Nessa perspectiva, buscou-se descrever como se dá a estruturação e desenrolar de vínculos (estrutura topológica) entre indivíduos em uma rede configurada pela gangue estudada.

Foi utilizado no programa, o método de agrupamento pautado no algoritmo de Clauset, Newman e Moore (2004), o qual tem como premissa de que em todas as equaçóes, cada grupo possui somente um pico ao longo do algoritmo, pois quando o maior grupo se torna negativo, ou seja, a partir do momento em que se alcançou o seu ápice de relacionamentos, todos os módulos só podem decrescer (CLAUSET, NEWMAN, MOORE, 2004). O mapa gráfico foi elaborado segundo o modelo de Sugiyama (1987).

\section{Resultados e Discussões}

As 225 ocorrências (universo de ocorrências desconsiderando apenas os crimes de menor potencial ofensivo) que compuseram o escopo da pesquisa permitiram identificar 371 participaçóes e coparticipaçóes, com atuaçáo de 130 agentes. Esta conformação permite afirmar que há uma prática de crimes de maneira reiterada e a coparticipaçáo na prática dos delitos, configurando-se ao conceito de gangue.

A Figura 2 é um diagrama que apresenta um mapa topológico no qual estáo representados os vínculos criminais entre os autores de delito que compóem gangue do Alto Vera Cruz. A rede foi construída a partir da ligaçáo entre indivíduos pela participação em um mesmo evento de defesa social.

A gangue foi representada na Figura 2 por meio de um grafo, no qual os seus vértices correspondem aos indivíduos e as arestas pelos relacionamentos catalogados pela coautoria de eventos criminais num mesmo boletim de ocorrência. $\mathrm{O}$ grafo possui 123 vértices e 211 arestas, sendo que suas principais medidas de centralidade estão presentes na Tabela a seguir.

Cada vértice possui uma medida de centralidade, que define sua posiçáo na estrutura da rede e que permite inferir sobre a importância do ator representado pelo vértice. As medidas de centralidade 
são comumente abordadas como medidas de atividade na rede. Quanto mais central com relação ao grau, mais ativo é um indi- víduo na estrutura.

O grau mínimo de todos os vértices

\section{Figura 2 - Mapa topológico da rede de relacionamentos dos componentes da Gangue do Alto Vera Cruz}

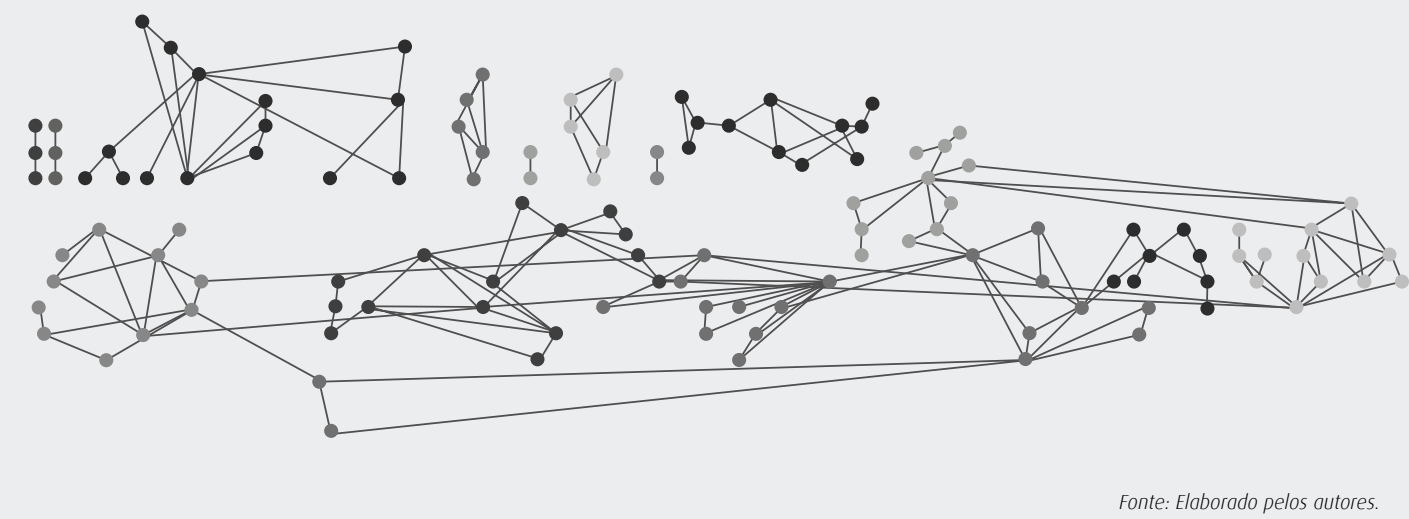

presentes no grafo é 1 , o que indica que todos os elementos representados possuem pelo menos uma ligação entre si. A média de ligaçôes é 3 e o máximo de ligaçôes presentes na rede é de 10 (indivíduo 36) e a segunda maior de 9 ligaçóes (indivíduo 37). Estes indivíduos se apresentam como agentes de concentraçáo das conexôes de rede da gangue em estudo, uma vez que ambos somam 19 ligaçóes com os demais membros. Um ator na rede que concentra muitas informações e ligaçóes a ele direcionadas pode ser considerado proeminente, tendo prestígio em meio à rede analisada (TOMAÉL e MARTELETO, 2006).

A medida de centralidade de intermediação mostra certo controle do ator sobre o fluxo de informaçáo e recursos na estrutura. A centralidade de intermediaçáo máxima presente na rede é 933,733 , a qual se refere ao indivíduo 37, que possui grau 9. Essa medida reflete quais indivíduos são mais importantes para a conexão entre os membros da rede, visto que sáo mais centrais quanto às ligaçóes entre dois outros componentes da gangue. Seu papel central faz com que este ator seja de extrema importância na articulaçáo da gangue como uma rede social, uma vez que, indiferente do número de ligaçóes que este possua, seu posicionamento garante que o mesmo esteja no caminho entre diferentes vértices (autores). Hanneman (2001) considera um ator de posiçáo de intermediaçáo numa rede como sendo uma maneira de se alcançar os demais autores desta rede, dado seu posicionamento ao longo dos caminhos geodésicos entre os vértices.

A centralizaçáo da rede em poucos integrantes atua como um fator de baixa resiliência, uma vez que potencializa o impacto de um determinado choque a partir da retirada de membros estratégicos (BAKKER; RAAB; MILWARD, 2011). 


\section{Tabela 1 - Resumo das medidas de centralidade do grafo que representa a Gangue do}

Alto Vera Cruz

\begin{tabular}{l|c}
\hline Medida de Centralidade & Valor \\
\hline Grau (mínimo) & 1,000 \\
\hline Grau (máximo) & 10,000 \\
\hline Grau (média) & 3,122 \\
\hline Grau (mediana) & 3,000 \\
\hline Centralidade de intermediação (mínimo) & 0,000 \\
\hline Centralidade de intermediação (máximo) & 933,733 \\
\hline Centralidade de intermediação (média) & 96,667 \\
\hline Centralidade de intermediação (mediana) & 0,000 \\
\hline Centralidade de proximidade (mínimo) & 0,002 \\
\hline Centralidade de proximidade (máximo) & 1,000 \\
\hline Centralidade de proximidade (média) & 0,084 \\
\hline Centralidade de proximidade (mediana) & 0,003 \\
\hline Centralidade de autovetor (mínimo) & 0,000 \\
\hline Centralidade de autovetor (máximo) & 0,069 \\
\hline Centralidade de autovetor (média) & 0,008 \\
\hline Centralidade de autovetor (mediana) & 0,003 \\
\hline
\end{tabular}

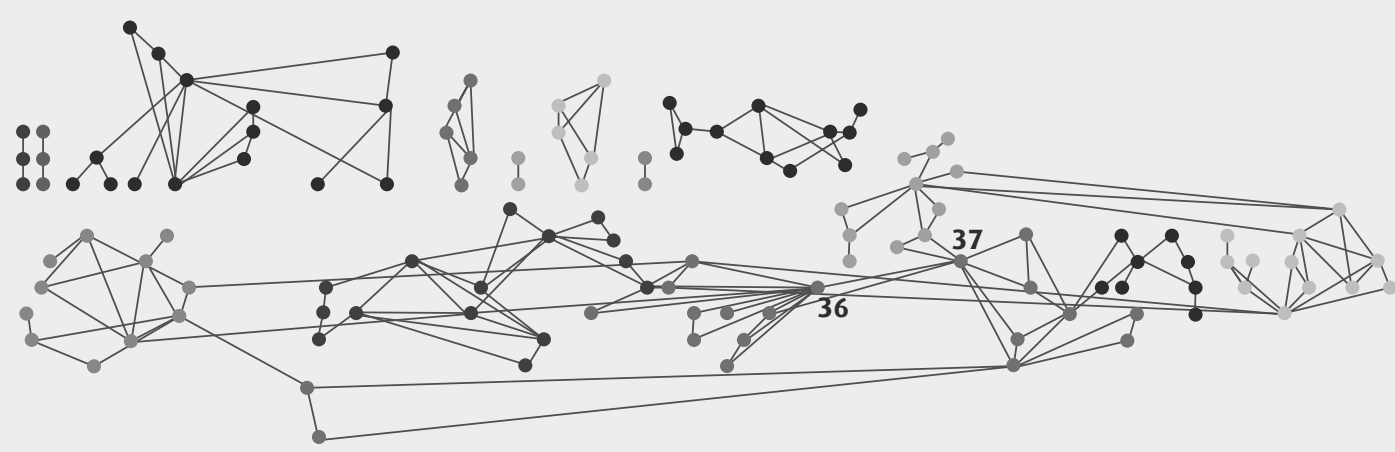


Assim, o indivíduo 37, por exemplo, por se destacar como ator em centralidade de grau e na centralidade de intermediaçáo é um grande articulador na gangue e também é um ator muito ativo. Esse tipo de ator por suas características pode também chamado de $h u b^{1}$. Essas informaçóes ensinam muito sobre a articulação de uma gangue. Apesar de haver diversos indivíduos participantes, o uso da análise de redes sociais deixa claro quem possui poder, capacidade de articulação e influência na estrutura reticular. Em termos práticos e em relação à resiliência da gangue, a retirada desse indivíduo da estrutura da gangue (por meio da prisão, por exemplo) poderia fragmentar a estrutura em subgrupos desconectados. Assim, o indivíduo também pode ser um cutpoint ${ }^{2}$ da rede.

A centralidade de proximidade máxima é 1,000 , sendo este parâmetro referente à influência de ator na estrutura reticular. Assim, o valor máximo da centralidade de proximidade, expressa os indivíduos mais influentes na gangue.

A centralidade de autovetor permite classificar os vértices como mais centrais na medida em que eles estabeleçam relaçôes com elementos que também estejam em uma posição central. $\mathrm{O}$ maior valor encontrado 0,069 referiu-se ao indivíduo 37 (grau 9). Esta informação corrobora a importância deste indivíduo para a rede em análise, uma vez que além de possuir uma posição de intermediação entre os diferentes vértices (autores), o mesmo se relaciona a outros autores também de grande importância para a rede. Desta for- ma, pode-se afirmar que, além de extensa, a rede deste autor apresenta relativo grau de sofisticação no contexto analisado.

A distância geodésica média entre os vértices do grafo é 4,72 que indica o menor caminho médio que liga os autores envolve cinco arestas, ou seja, cinco atores que compartilham coautorias direta ou indiretamente. A distância geodésica máxima, ou diâmetro do grafo, é de 12 , que indica o relacionamento máximo compartilhado entre os componentes da gangue, sendo a colaboração mais longa entre os membros.

A densidade do grafo é 0,026 , que indica o nível geral de ligaçóes entre os pontos de um grafo, mostrando que poucos pontos estáo ligados uns aos outros.

A modularidade do grafo obtida foi de 0,756 , sendo que os valores próximos a 1 indicam uma boa qualidade de agrupamento, o que pode ser atribuído a grande quantidade de arestas no interior dos grupos. Sendo assim, a gangue é composta por 14 comunidades, sendo uma principal com 77 indivíduos e outras marginais com menor número de atores. Pode-se inferir que existe um núcleo duro de atores prolíficos (mais produtivos) e outros indivíduos menos ativos que formam outros grupos menores, o que pode ser explicado também pelos diferentes níveis de centralidade de proximidade e de intermediaçáo na gangue. Há autores que apresentam maiores links em meio à gangue, sendo, portanto, mais centrais nas atividades da mesma.

1 Hub seria um ator altomente conectado a vórios outros atores que contribuem significativamente para diminuir a distôncio entre os grupos e indivíduos do rede (FREITAS; PEREIRA, 2005).

2 Ator com potencial para desconector a rede. 
Em relação à identificação de comunidades, o grafo divide-se em 14 subgrupos por cluster, usando o algoritmo Clauset-Newman-Moore, que representam relaçôes internas, sendo que destes subgrupos há oito desconexóes em relação à rede, o maior número de conexôes é de 77 indivíduos. Os sete indivíduos que não se conectam pelos vínculos criminais ao restante da rede não estáo foram contemplados pela análise.

\section{Tabela 2 - Métricas do Grafo que representa a Grangue do Alto Vera Cruz}

\begin{tabular}{l|c}
\hline Métrica & Valor \\
\hline Distância Geodésica média & 4,72 \\
\hline Distância Geodésica máxima (Diâmetro) & 12 \\
\hline Densidade & 0,026 \\
\hline Modularidade & 0,756
\end{tabular}

\section{Conclusão}

$\mathrm{O}$ artigo descreveu a estrutura de indivíduos que formam uma gangue oriunda de um aglomerado subnormal de Belo Horizonte, com atuação em diversas regióes da cidade além de outros municípios.

A questão estrutural foi analisada a partir de uma revisão bibliográfica da análise de redes sociais para o estudo de grupos criminosos, utilizando-se a teoria de grafos como subsídio.

Os resultados permitiram identificar os principais indivíduos em termos de posiçóes centrais na estrutura do grupo, o que se deve aos seus vínculos criminais com outros componentes.

Os resultados de medidas de centrali- dade (grau, centralidade de proximidade, centralidade de intermediação, centralidade de autovetor) e métricas (distância geodésica, diâmetro, densidade e modularidade) permitiram identificar que a gangue representa uma rede social coesa, em que é possível por meio da metodologia proposta conhecer os principais elementos em termos de importância para os vínculos criminais na gangue, notadamente quanto ao nível de atividade e articulação.

Apesar de haver diversos indivíduos participantes, o uso da análise de redes sociais deixa claro quem possui poder, capacidade de articulação e influência na estrutura reticular, o que pode contribuir para estratégias investigativas e de combate às organizaçóes criminosas. Existe ainda, conforme abordado por Baker; Faulkner (1993), potencial para em trabalhos fu- 
turos avaliar a mensuração do nível de atividade dos componentes de um grupo criminoso em processos judiciais, a fim de melhor individualizar as condutas e permitir uma penalizaçáo adequada, conforme participação, articulação e prestígio de cada componente.

Academicamente, o trabalho contribui com o estudo de redes sociais, agregando informações de organizaçôes criminosas com emprego de técnicas matemáticas. Esses recursos garantem uma robustez científica ao melhor entendimento de gangues e outras atividades criminosas.

Em termos operacionais, a análise utilizada no artigo pode ser empregada como elemento de investigação policial, em especial, na identificação de estruturas de

\section{Referências Bibliográficas}

ABRAMOVAY, Miriam. Gangues, galeras, chegados e rappers: juventude, violência e cidadania nas cidades da periferia de Braślia. Editora Garamond, 1999.

AMORIM, Carlos. CV-PCC: a irmandade do crime. Editora Record, 2003.

ASHBURY, Herbert. Gangs of New York: an Informal History of the Underworld. 1927.

BAKER, W. E.; FAULKNER, R. R. The Social Organization of Conspiracy: Illegal Networks in the Heavy Electrical Equipment Industry. American Sociological Review, 58:837-860, 1993.

BAKER, W; FALUKNER, R. Social Networks and loss of capital. Oxford. Nova lorque. Oxford University Press. 2004.

BAKKER, R.; RAAB, J:; MILWARD, H.B. A preliminary theory of dark network resilience. Journal of Policy Analysis and Management, 31:33-62, 2012. organizaçóes criminosas que complementem informações de individualização das condutas com a importância dos indivíduos nas redes as quais eles compóem; os vínculos entre autores de delitos; posiçóes de centralidade ou periferia numa determinada gangue; além de inferir a estrutura hierárquica entre os elementos.

Longe de buscar exaurir as discussóes sobre o tema, devido seu caráter pioneiro na análise do caso em questão, este estudo pode ser utilizado como referência metodológica para aprofundamentos em trabalhos posteriores. Além disso, existe potencial em incrementar políticas públicas de segurança focadas na prevenção criminal e combate à criminalidade que envolvam gangues e outras organizaçóes criminosas.

BARCELlOS, Caco. Abusado: o dono do morro Dona Marta. Editora Record, 2003.

BAVELAS, A. (1950) Communication patterns in task oriented groups. Journal of the Acoustical Society of America, v. 22, pp. 725-730.

BEATO, Cláudio Chaves et al. Conglomerados de homicídios e o tráfico de drogas em Belo Horizonte, Minas Gerais, Brasil, de 1995 a 1999. Cadernos de Saúde Pública, v. 17, p. 1163-1171, 2001.

BEATO, Cláudio; ZILLI, Luís Felipe. A estruturação de atividades criminosas. Um estudo de caso. Revista Brasileira de Ciências Sociais, v. 27, n. 80, 2012.

BELIZARIO, IVar Vargas. Avaliação de algoritmos de agrupamento em grafos para segmentação de imagens. 2012. Dissertação de Mestrado. Universidade de São Paulo. 
BERGIANTE, N. C. R. et al. Aplicação de uma proposta de medida de centralidade para avaliação de malha aérea de uma empresa do setor de transporte aéreo brasileiro. Revista de Literatura dos Transportes, vol. 5, ח. 4, pp. 119-135, 2011.

BONACHIC, P. (1987) Power and Centrality: A Family of Measures. The American Journal of Sociology, v. 92, ก. 5, p. 1170-1182.

BORDIN, Andréa S.; GONÇALVES, Alexandre L.; TODESCO, José Leomar. Análise da colaboração científica departamental através de redes de coautoria. Perspectivas em Ciência da Informação, v. 19, n. 2, p. 37-52, 2014.

ClaUSET, Aaron; NEWMAN, Mark E. J:; MOORE, Cristopher. Finding community structure in very large networks. In: Physical review E, v. 70, n. 6, 2004.

COMET, C. Anatomy of a Fraud: Trust and Social Networks. Bulletin de Méthodologie Sociologique, 110:45-57, 2011.

ERICKSON, B. Secret Societies and Social Structure. Social Forces. 60. p. 188-210, 1981

FREEMAN, L C. Centrality in Social Networks: Conceptual Clarification. In: Social Networks 1, 215-239,1979

FREITAS, M. C.; PEREIRA, H. B. de B. Contribuição da análise de redes sociais para o estudo sobre os fluxos de informações e conhecimento. Encontro Nacional de Ciência da Informação, Salvador, nov. 2005

HANNEMAN, Robert A. Introduction to social network methods. 2001. Disponível em: http://faculty.ucr. edu/ hanneman/SOc157/NETtEXT.PDF Acesso em 26 ago. 2003.

HIGGINS, Silvio Salej; RIBEIRO, Antonio Carlos Andrade. Análise de redes em Ciências Sociais. 2018.

JENNINGS, H. Leadership and isolation: A study of personality in interpersonal relations. Nova lorque. Longmans, Green and Company, 1943.

KREBS, V. Mapping Networks of Terrorist Cells. Connec- tions, 24:43, 52, 2001.

LAZEGA, Emmanuel; HIGGINS, Silvio Salej. Redes sociais e estruturas relacionais. 2014.

LEEDS, Elizabeth. Cocaína e poderes paralelos na periferia urbana brasileira. Um século de favela. FGV ed., Rio de Janeiro, 1998.

MALM, A. et al. Pushing the Ponzi: The rise and fall of a network fraud. In:

MORSELLI, C. (ed), Crime and Networks. NY: Routledge, 2013.

MARQUES, Eduardo Cesar. Estado e redes sociais: permeabilidade e coesão nas políticas urbanas no Rio de Janeiro. Editora Revan, 2000.

MLLWARD, H.B.; RAAB, J. Dark Networks as organizational problems: elements of a theory. International Public Management Journal, 9, p.333-360, 2006.

MISSE, Michel. As ligações perigosas: mercado informal ilegal, narcotráfico e violência no Rio. Contemporaneidade e educação, v. 1, n. 2, p. 93-116, 1997.

MISSE, Michel. Sobre a acumulação social da violência no Rio de Janeiro. Civitas-Revista de Ciências Sociais, v. 8, ก. 3, 2008.

MOBERG, F; FOLKE, C. Ecological goods and services of coral reef ecosystems. Ecological Economics, 29, p.215233. 1999.

MORENO, Jacob Levy; WHITIN, Ernest Stagg; JENNINGS, Helen Hall. Application of the group method to classification. National committee on prisons and prison labor, 1932.

MORSELLI, C. Inside Criminal Networks. New York: Springer, 2009.

PAES MANSO, Bruno. 0 homem $\mathbf{x}$ : uma reportagem sobre a alma do assassino em São Paulo. Editora Record, 2005. 
PARREIRAS, Fernando Silva et al . Redecl: colaboração e produção cientíica em ciência da informação no Brasil. Perspect. ciênc. inf., Belo Horizonte, v. 11, n. 3, p. 302-317, Dec. 2006 . Available from <http:// www.scielo.br/scielo.php?script=sci_arttext\&pi$\mathrm{d}=\mathrm{S} 1413-99362006000300002 \mathrm{lng}=\mathrm{en} 8 \mathrm{n} \mathrm{m}=\mathrm{is0}>$. access on 26 May 2018. http://dx.doi.org/10.1590/ S1413-99362006000300002.

RAAB, J.; MILWARD, H.B. Dark networks as problems. Journal of Public Administration Research and Theory. 13, p. 413-440, 2003.

RUHNAU, Britta. Eigenvector-centrality-a node-centrality?. Social networks, v. 22, п. 4, p. 357-365, 2000.

SÁNCHEZ-JANKOWSKI, Martín. As gangues e a estrutura da sociedade norte-americana. Revista Brasileira de Ciências Sociais, v. 12, n. 34, pp. 25-37, 1997.

SANCHEZ-JANKOWSKI, Martin. Islands in the street: Gangs and American urban society. Univ of California Press, 1991.
SPARROW, M.K. The application of network analysis to criminal intelligence: An assessment of the prospects. In: Social Networks, 13, p. 251-274, 1991.

SUGIYAMA, Kozo. A cognitive approach for graph drawing. In: Cybernetics and Systems. 18(6): 447-488. 1987.

THRASHER, Frederic Milton; SHORT, James Franklin. The Gang. A Study of 1,313 Gangs in Chicago... Abridged and with a New Introduction by James F. Short.[With Illustrations.]. University of Chicago Press, 1963.

TOMAÉL, Maria Inês; MARTELETO, Regina Maria. REDES SOCIAIS: posições dos atores no fluxo da informação. $\mathbf{R}$. Eletr. Bibliotecon. Ci. Inf., Florianópolis, n. esp., $1^{0}$ sem. 2006.

ZORBAUGH, Harvey Warren. The gold coast and the slum. V. 227. Chicago: University of Chicago Press, 1929. 


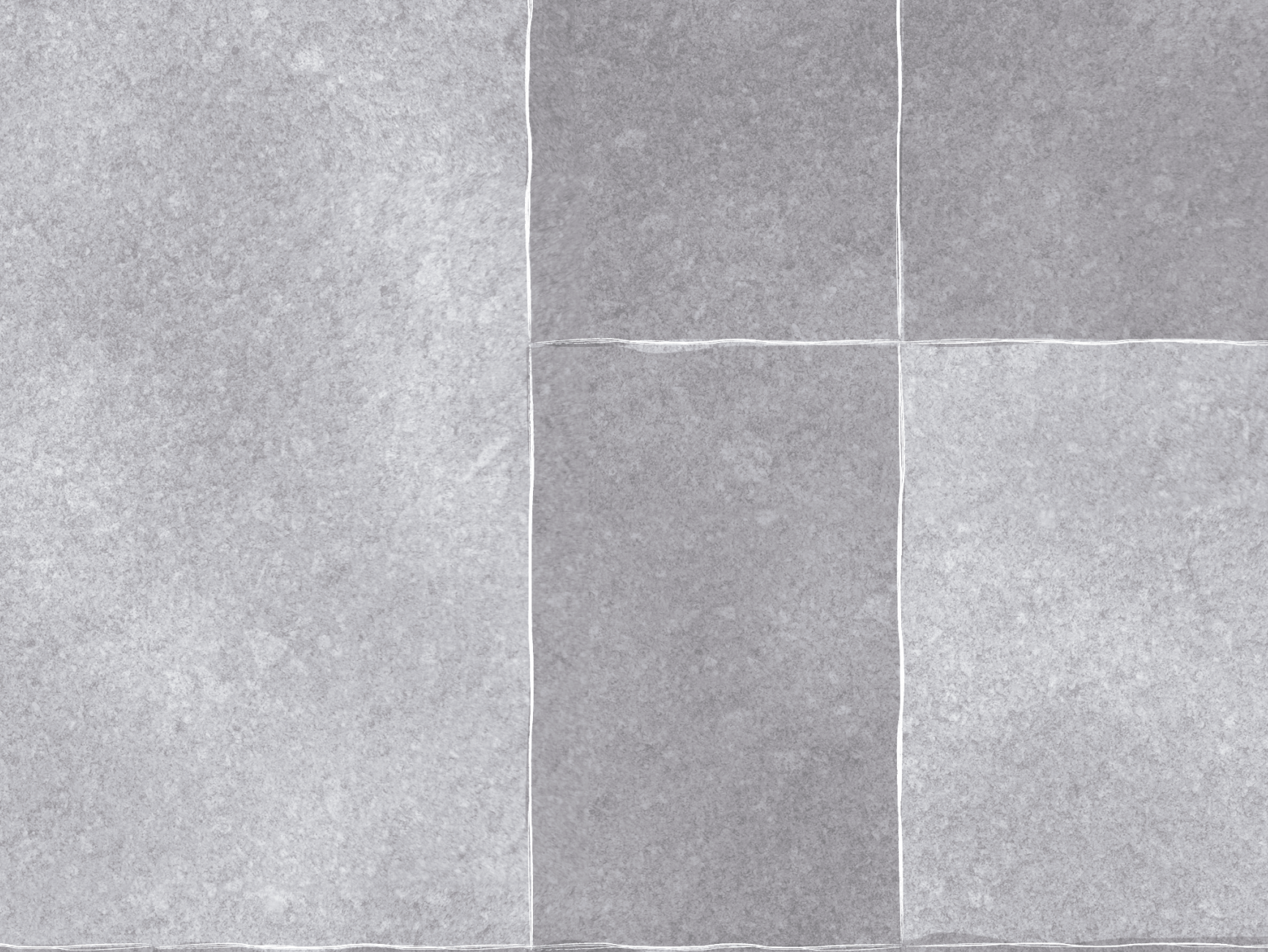

